\title{
Response of Bifidobacterium Species to Growth Promoters in Human and Cow Milk
}

\author{
BRYON W. PETSCHOW AND ROBERT D. TALBOTT
}

Mead Johnson Research Center, Evansville, Indiana 47721

\begin{abstract}
We used an in vitro assay to study and compare the growth-promotional activity of protein and nonprotein components in human milk (HM) and cow milk (CM) samples for infant strains of Bifidobacterium species. HM samples varied considerably in growth-promotion activity for Bifidobacterium bifidum var pennsylvanicus, Bifidobacterium infantis, and Bifidobacterium breve. Pooled CM samples showed similar but less variable levels of activity when compared with HM samples. Separation of milk samples by ultrafiltration into protein nitrogen and nonprotein nitrogen (NPN) fractions revealed that the bifidobacteria growth-promotion activity of HM was associated primarily with the NPN fraction, whereas activity in CM whey was found in both protein nitrogen and NPN fractions. Testing of purified $\mathrm{CM}$ whey proteins showed that $\alpha$-lactalbumin and lactoferrin were potent growth promoters, showing greater activity for $B$. infantis and $B$. breve than for two strains of $B$. bifidum. Conversely, Nacetylglucosamine and purified gastric mucin were highly active for $B$. bifidum strains but inactive for other Bifidobacterium species. Collectively, the data indicate that both protein nitrogen and NPN factors in HM and CM promote the growth of bifidobacteria and suggest that Bifidobacterium species differ in responsiveness to protein and oligosaccharide growth promoters. (Pediatr Res 29: 208-213, 1991)
\end{abstract}

\section{Abbreviations}

HM, human milk

CM, cow milk

NAcGlu, N-acetyl-D-glucosamine

ED, electrodialyzed

NPN, nonprotein nitrogen

$\mathrm{PN}$, protein nitrogen

LF, lactoferrin

$\alpha$-LA, $\alpha$-lactalbumin

$\beta$-LG, $\beta$-lactoglobulin

BIg, bovine immunoglobin

The intestinal microflora of the neonate becomes established within several weeks after birth (1). The composition of this microflora is relatively simple and is believed to be influenced by diet because the fecal flora of breast-fed infants differs from that of formula-fed infants. Thus, although all studies are not in complete agreement, many have found that stool from breastfed infants has a lower $\mathrm{pH}$ and a higher proportion of Grampositive nonsporeforming rods, especially bifidobacteria, when compared with their formula-fed counterparts (1-5). Some re-

Received June 12, 1990; accepted September 21, 1990.

Correspondence: Bryon W. Petschow, Mead Johnson Research Center, BristolMyers Squibb Co., 2400 W. Lloyd Expressway, Evansville, IN 47721. searchers have postulated that such differences in intestinal microflora composition may account in part for the greater resistance of breast-fed infants to enteric infection compared with formula-fed infants $(6,7)$. Bifidobacteria may contribute to this protective capacity by establishing an acetate buffer in the intestinal tract of the infant (8) that may inhibit potential pathogens (9) and thus enhance natural resistance to enteric infections.

HM contains specific factors that might serve to modulate the composition of the intestinal microflora. These include numerous antiinfective components as well as specific factors that promote the growth of bifidobacteria (10-12). Gyorgy and coworkers found that HM, but not $\mathrm{CM}$, contains factors that promote the growth of $B$. bifidum var. pennsylvanicus $(13,14)$. These factors were later identified as glycoproteins and oligosaccharides that contain NAcGlu $(10,11,15,16)$. Results from other studies indicate that bifidus growth-promotion activity may also be associated with polypeptide components of HM (17) or bovine casein digest (18). Although most of these studies have characterized bifidus growth-promotion activity by using $B$. bifidum var. pennsylvanicus, a relatively rare component of the intestinal microflora of the infant, the nature of growth promoters in $\mathrm{HM}$ and $\mathrm{CM}$ for the major intestinal species of bifidobacteria has not been extensively studied.

In a previous report (19), we showed that CM was capable of promoting the growth of several human species of bifidobacteria, albeit at somewhat lower levels than HM. This activity was associated primarily with the CM whey fraction and was equal to $\mathrm{HM}$ whey in activity, suggesting that the lower activity of $\mathrm{CM}$ may be due to the lower proportion of whey to casein in $\mathrm{CM}$ $(20: 80)$ relative to HM (70:30). Our present study further characterizes the bifidobacteria growth-promoting activity of $\mathrm{HM}$ and $\mathrm{CM}$ by comparing the activity in protein and nonprotein fractions for several common intestinal species of bifidobacteria.

\section{MATERIALS AND METHODS}

Milk samples. HM samples were obtained from 10 healthy nursing mothers at stages of lactation ranging from 1 to $6 \mathrm{mo}$ postpartum. CM samples were obtained from bulk milk tanks of eight separate farms located in Missouri, Minnesota, Nebraska, and Texas (two farms per state). Raw milk samples were frozen at $-75^{\circ} \mathrm{C}$ until needed. Skim milk samples were prepared by centrifuging freshly thawed milk samples at $12000 \times g$ for 30 min and aspirating the resulting supernatant below the fat layer. ED whey was supplied by the Mead Johnson Nutritional Group (Evansville, IN). Milk and whey samples were sterilized by membrane filtration (Gelman Sciences, Inc., Ann Arbor, MI) before testing in the growth-promotion assay.

CM whey (ED whey) and HM were separated into high molecular weight and low molecular weight fractions by ultrafiltration using an Amicon model 52 (Amicon Corp., Danvers, MA) ultrafiltration cell and a YM-10 membrane (mol wt cutoff = $10000)$. The initial filtrate was filter-sterilized and stored at $-20^{\circ} \mathrm{C}$. The initial retentate fractions $(10 \%$ of original volume) of $\mathrm{HM}$ and $\mathrm{CM}$ whey were washed 10 times with saline to further 
remove low molecular weight components and reconstituted to the original volume of the unfractionated material to restore proteins to their original concentration. This washed retentate was filter-sterilized and frozen at $-20^{\circ} \mathrm{C}$ until needed. The filtrate and retentate fractions were assayed for total nitrogen content by Kjeldahl analysis and referred to as the NPN and PN fractions, respectively.

The profile of proteins in HM and ED CM whey (before and after ultrafiltration) and the purity of preparations of CM whey proteins were assessed by SDS-PAGE in $12 \%$ gels. Samples were prepared in sample buffer ( $2 \%$ SDS, $10 \%$ glycerol, $5 \%$ 2-mercaptoethanol, and bromophenol blue in $0.0625 \mathrm{M}$ Tris-hydrochloride, $\mathrm{pH} 6.8$ ) at $1.5 \mathrm{mg} / \mathrm{mL}$ concentration and solubilized by boiling for $5 \mathrm{~min}$ before applying to vertical slab gels. After electrophoresis, gels were stained with Coomassie brilliant blue R250, destained with water:methanol:acetic acid (5:4:1), and appropriate lanes were scanned on a Bio-Rad model 620 (BioRad Laboratories, Richmond, CA) video densitometer.

The NPN fraction of HM was found to be free of detectable milk proteins by PAGE analysis (data not shown) and contained $24 \%$ of the nitrogen in the unfractionated HM, which is similar to previously published values for NPN in HM (20). The NPN fraction of $\mathrm{CM}$ whey was free of detectable whey proteins by PAGE analysis (data not shown). The protein banding patterns of the whey PN fraction and unfractionated CM whey were virtually identical. The nitrogen content of the NPN fraction was about $19 \%$ of the total nitrogen in the starting material, which compares favorably with published values for NPN in CM whey (21).

Bifidobacteria strains. The following strains of bifidobacteria were purchased from the American Type Culture Collection (Rockville, MD) for use in this study: $B$. bifidum var. pennsylvanicus (ATCC 11863), B. bifidum (ATCC 15696), B. breve (ATCC 15700, type strain), B. infantis (ATCC 15697, type strain), and $B$. longum (ATCC 15708). These strains were originally isolated from stool of human infants. Stock cultures were grown in phosphate-buffered Reinforced Clostridial Medium (Difco Laboratories, Detroit, MI) under anaerobic conditions and maintained long-term in lyophilized form as previously described (19).

Bifidobacteria growth-promotion assay. The growth-promotion activity of test samples for strains of bifidobacteria was measured by an acid titration method (19) after growth in Norris medium (22) without added HM, referred to here as basal Norris medium. Briefly, tubes containing $4 \mathrm{~mL}$ of prereduced basal Norris media with or without test samples were inoculated with test strains of bifidobacteria (about $1 \times 10^{6}$ colony forming units)

Table 1. Growth of Bifidobacterium subspecies in Norris medium containing HM and optimal growth medium

\begin{tabular}{|c|c|c|c|c|c|}
\hline \multirow[b]{2}{*}{ Organism } & \multirow[b]{2}{*}{ Medium* } & \multicolumn{2}{|c|}{$\begin{array}{c}\text { Growth as } \\
\text { OD at } 610 \\
n m\end{array}$} & \multicolumn{2}{|c|}{$\begin{array}{c}\text { Growth as } \\
\text { units } \dagger\end{array}$} \\
\hline & & $24 \mathrm{~h}$ & $48 \mathrm{~h}$ & $24 \mathrm{~h}$ & $48 \mathrm{~h}$ \\
\hline \multirow{3}{*}{$\begin{array}{l}\text { B. bifidum var. penn- } \\
\text { sylvanicus }\end{array}$} & Control & 0.01 & 0.01 & 0.012 & 0.011 \\
\hline & Norris + HM & 0.74 & 1.09 & 0.335 & 0.560 \\
\hline & TPY & 0.01 & 0.03 & 0.000 & 0.003 \\
\hline \multirow[t]{3}{*}{ B. infantis } & Control & 0.33 & 0.54 & 0.222 & 0.540 \\
\hline & Norris + HM & 1.31 & 1.44 & 0.623 & 0.810 \\
\hline & TPY & 0.02 & 0.91 & 0.000 & 0.233 \\
\hline \multirow[t]{3}{*}{ B. breve } & Control & 0.15 & 0.10 & 0.230 & 0.312 \\
\hline & Norris + HM & 1.06 & 1.10 & 0.500 & 0.847 \\
\hline & TPY & 0.85 & 0.98 & 0.310 & 0.351 \\
\hline
\end{tabular}

* Test media included basal Norris medium with added saline (control) or HM and trypticase-peptone-yeast extract medium (TPY).

$\dagger$ Units defined as mmol of $\mathrm{NaOH}$ required to neutralize the acid produced per $4 \mathrm{~mL}$ culture after indicated incubation period.

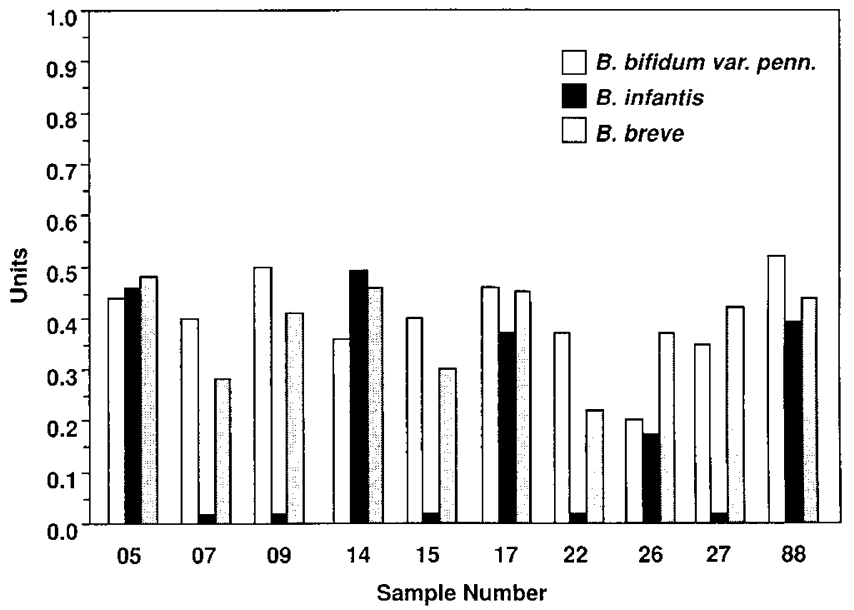

Fig. 1. Growth-promotion activity of individual HM samples ( $1 \mathrm{~mL} /$ $4 \mathrm{~mL}$ assay) for three strains of bifidobacteria. Units of activity are defined as mmol of $\mathrm{NaOH}$ required to neutralize the acid produced by a 4-mL culture after $48 \mathrm{~h}$. The data shown represent the means of duplicate determinations after correcting for control growth using $1 \mathrm{~mL}$ saline/4 mL culture.

and incubated under anaerobic conditions. The amount of acid produced during a 48-h incubation was measured in cell-free supernatants and served as an indicator of bacterial growth and metabolism. Growth-promotion activity was expressed in units defined as the mmol of $\mathrm{NaOH}$ required to neutralize the acid produced in a $4 \mathrm{~mL}$ culture by the test strain during a 48 -h incubation period.

Unfractionated HM and CM whey were tested in the growthpromotion assay at $2 \mathrm{mg}$ protein $/ \mathrm{mL}(0.2$ and $0.24 \mathrm{~mL} / \mathrm{mL}$ assay volume for $\mathrm{HM}$ and $\mathrm{CM}$ whey, respectively). The NPN and $\mathrm{PN}$ fractions were tested at the same volume used for testing the initial unfractionated material to allow relative comparisons of samples for growth-promotion activity. Control tubes containing saline in place of test samples were included in all experiments. Unless specifically indicated, all test samples were sterilized by membrane filtration (Gelman Sciences, Inc.) and tested in duplicate in at least two experiments.

Materials. BSA, $\alpha-\mathrm{LA}, \beta-\mathrm{LG}$, and NAcGlu were purchased from Sigma Chemical Co. (St. Louis, MO), reconstituted in sterile saline, and filter-sterilized for use in growth-promotion assays. BIg (Calbiochem-Behring, San Diego, CA) were treated in a similar manner. Bovine LF (AlaPharm, Palmerston North, New Zealand) was dissolved in sterile PBS, centrifuged at 10000 $\times g$ for 10 min to remove particulate matter, and sterilized by membrane filtration.

Mucin oligosaccharides were partially purified from crude porcine gastric mucin (Orthana Kemisk Fabrik, Kastrup, Denmark) by a modification of the method of Veriyam and Hoskins (23). Briefly, reconstituted crude mucin was centrifuged to remove cell debris. The soluble mucin oligosaccharides were extracted twice with $60 \%$ ethanol, dissolved in distilled water, and incubated at $\mathrm{pH} 1.5$ for $30 \mathrm{~min}$. Precipitated debris was removed by centrifugation. The mucin oligosaccharides were extracted from the supernatant a third time, extensively dialyzed, and lyophilized. The relative purity of the mucin oligosaccharides was assessed by comparison to starting material using Sephacryl S-200 chromatography (Pharmacia, Inc., Piscataway, NJ). Column fractions were monitored for carbohydrate levels by the method of Dubois et al. (24) and for protein content by a modification of the method of Lowry (25). Much of the contaminating low molecular weight carbohydrate and protein was removed by the extraction procedure, leaving a mucin preparation that was $18 \%$ protein by weight and primarily high molecular weight.

Statistical methods. Growth promotion data were analyzed by 
Table 2. Growth-promotion activity of ultrafiltration fractions from HM for bifidobacterium subspecies isolated from human infants

\begin{tabular}{llllll}
\hline & \multicolumn{5}{c}{ Growth-promotion activity (units) ${ }^{*}$ for: } \\
\cline { 2 - 5 } Fraction $\dagger$ & B. bifidum var. pennsylvanicus & \multicolumn{1}{c}{ B. bifidum } & B. infantis & B. breve & B. longum \\
\hline Control & $0.011 \pm 0.003$ & $0.094 \pm 0.007$ & $0.151 \pm 0.073$ & $0.139 \pm 0.079$ & $0.295 \pm 0.087$ \\
HM & $0.427 \pm 0.019 \ddagger$ & $0.192 \pm 0.193$ & $0.559 \pm 0.017 \ddagger$ & $0.648 \pm 0.013 \ddagger$ & $0.725 \pm 0.009 \ddagger$ \\
NPN (filtrate) & $0.634 \pm 0.012 \ddagger \S$ & $0.746 \pm 0.012 \ddagger \S$ & $0.228 \pm 0.016$ & $0.357 \pm 0.013 \ddagger$ & $0.470 \pm 0.039 \|$ \\
PN (retentate) & $0.313 \pm 0.012 \ddagger$ & $0.165 \pm 0.106$ & $0.221 \pm 0.011$ & $0.272 \pm 0.006 \|$ & $0.364 \pm 0.087$ \\
\hline
\end{tabular}

* Units defined as the amount of $\mathrm{NaOH}$ required to neutralize the acid produced per $4 \mathrm{~mL}$ culture after a 48 -h incubation. Results are given as means $\pm \mathrm{SD}$ of at least quadruplicate samples.

$\dagger$ All fractions tested at $0.20 \mathrm{~mL} / \mathrm{mL}$ assay volume based on $2 \mathrm{mg}$ protein $/ \mathrm{mL}$ for $\mathrm{HM}$.

$\$$ Different from saline control $(p<0.01)$.

$\S$ Different from HM and retentate $(p<0.01)$.

॥ Different from saline control $(p<0.05)$

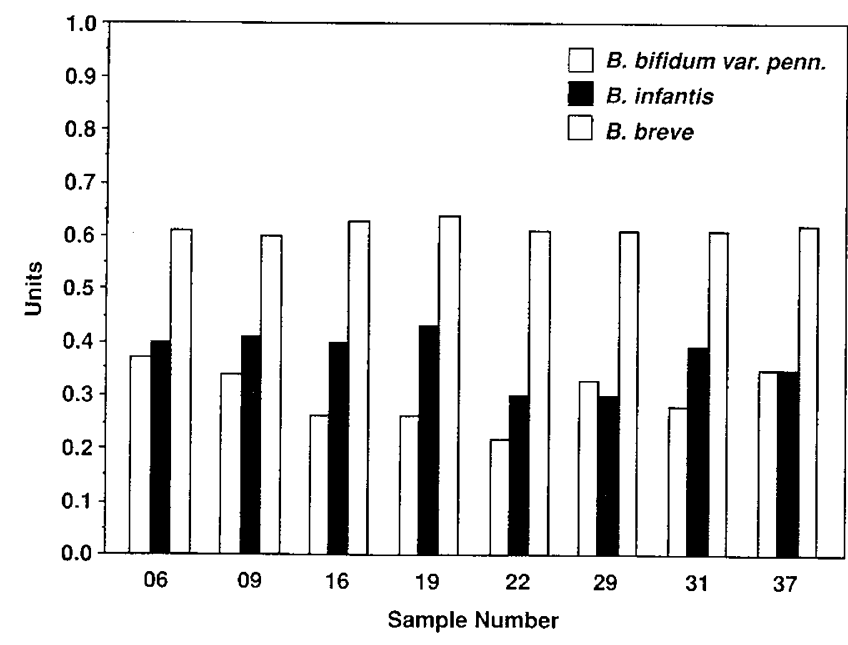

Fig. 2. Growth-promotion activity of $\mathrm{CM}$ samples ( $1 \mathrm{~mL} / 4 \mathrm{~mL}$ assay) for three strains of bifidobacteria. Units of activity defined in Figure 1. The data shown represent the mean of duplicate determinations after correcting for control growth using $1 \mathrm{~mL}$ saline $/ 4 \mathrm{~mL}$ culture.

a one-way analysis of variance using Statgraphics statistical software package (STSC, Inc., Rockville, MD). Multiple comparisons were made using a multiple range test based on confidence intervals and differences between sample means.

\section{RESULTS}

Comparison of Bifidobacteria growth in Norris and optimal growth media. Basal Norris medium containing HM promoted the growth of $B$. bifidum var. pennsylvanicus, $B$. infantis, and $B$. breve as indicated by steady increases in both turbidity and acid production when compared with control tubes containing basal Norris medium and saline (Table 1). The pH of cell-free supernatant decreased to about 4.7 and turbidity increased to at least
$1.0\left(\mathrm{~A}_{610}\right)$ by $48 \mathrm{~h}$. The growth of $B$. infantis and $B$. breve by 48 $\mathrm{h}$ in basal Norris medium containing HM was at least as good as growth achieved by $48 \mathrm{~h}$ in trypticase-peptone-yeast extract medium, which is accepted as an optimal growth medium for Bifidobacterium subspecies (26). Trypticase-peptone-yeast extract medium did not support the growth of $B$. bifidum var. pennsylvanicus. In all subsequent experiments, acid production by $48 \mathrm{~h}$ was used as the marker of cell growth in the growthpromotion assay.

Bifidobacteria growth-promotion activity in HM samples. Individual HM samples exhibited a high degree of variability in growth-promotion activity for $B$. bifidum var. pennsylvanicus, $B$. infantis, and $B$. breve (Fig. 1). The variability in activity was greatest for $B$. infant $i s$, with five HM samples showing no activity. All HM samples showed activity for $B$. bifidum var. pennsylvanicus and $B$. breve, although at varying levels. No consistent relationship was found in the level of growth-promotion activity in HM samples for each of the three test bifidobacteria strains.

Highly active HM from a single donor (no. 88) was partitioned by membrane ultrafiltration to determine the distribution of bifidobacteria growth-promotion activity among PN and NPN compartments. Ultrafiltration was chosen as the preferred method for practical fractionation of HM with negligible loss of growth-promotion activity. As shown in Table 2, the growthpromotion activity of HM was found primarily in the NPN fraction. The activity of HM NPN was significantly greater $(p<$ 0.05 ) than saline controls for $B$. bifidum var. pennsylvanicus, $B$. bifidum, $B$. breve, and $B$. longum, whereas HM retentate was active $(p<0.05)$ for only $B$. bifidum var. pennsylvanicus and $B$. breve. The NPN fraction was significantly more active $(p<0.05)$ than the PN fraction for $B$. bifidum var. pennsylvanicus, $B$. bifidum, and B. longum.

Growth-promotion activity of bulk tank CM samples. Growthpromotion activity was found in eight bulk tank CM samples for $B$. bifidum var. pennsylvanicus, $B$. infantis, and B. breve (Fig. 2). Activity was highest for $B$. breve for all samples. Growth-promotion activity varied only slightly among different $\mathrm{CM}$ samples

Table 3. Growth-promotion activity of ultrafiltration fractions from CM whey for Bifidobacterium subspecies isolated from human infants

\begin{tabular}{|c|c|c|c|c|c|}
\hline \multirow[b]{2}{*}{ Fraction $\dagger$} & \multicolumn{5}{|c|}{ Growth-promotion activity (units)* for: } \\
\hline & B. bifidum var. pennsylvanicus & B. bifidum & B. infantis & B. breve & B. longum \\
\hline Control & $0.016 \pm 0.005$ & $0.096 \pm 0.007$ & $0.112 \pm 0.054$ & $0.149 \pm 0.106$ & $0.297 \pm 0.074$ \\
\hline CM & $0.392 \pm 0.035 \ddagger$ & $0.645 \pm 0.016 \ddagger$ & $0.719 \pm 0.043 \ddagger$ & $0.787 \pm 0.056 \ddagger$ & $0.435 \pm 0.054 \ddagger$ \\
\hline NPN (filtrate) & $0.313 \pm 0.019 \pm$ & $0.312 \pm 0.019 \ddagger \S$ & $0.629 \pm 0.040 \ddagger$ & $0.701 \pm 0.048 \ddagger$ & $0.370 \pm 0.016$ \\
\hline PN (retentate) & $0.023 \pm 0.004$ & $0.338 \pm 0.009 \ddagger 8$ & $0.610 \pm 0.029 \neq \|$ & $0.640 \pm 0.047+$ & $0.354 \pm 0.006$ \\
\hline
\end{tabular}

* Units defined as the amount of $\mathrm{NaOH}$ required to neutralize the acid produced per $4 \mathrm{~mL}$ culture after a 48 -h incubation. Results are given as means $\pm \mathrm{SD}$ of at least quadruplicate samples.

† All fractions tested at $0.24 \mathrm{~mL} / \mathrm{mL}$ assay volume based on $2 \mathrm{mg}$ protein $/ \mathrm{mL}$ for $\mathrm{CM}$ whey.

$\ddagger$ Different from saline control $(p<0.01)$.

$\S$ Different from CM whey $(p<0.01)$.

|| Different from CM whey $(p<0.05)$. 
BIFIDOBACTERIA GROWTH BY MILK COMPONENTS

Table 4. Bifidobacteria growth-promotion activity of CM whey proteins

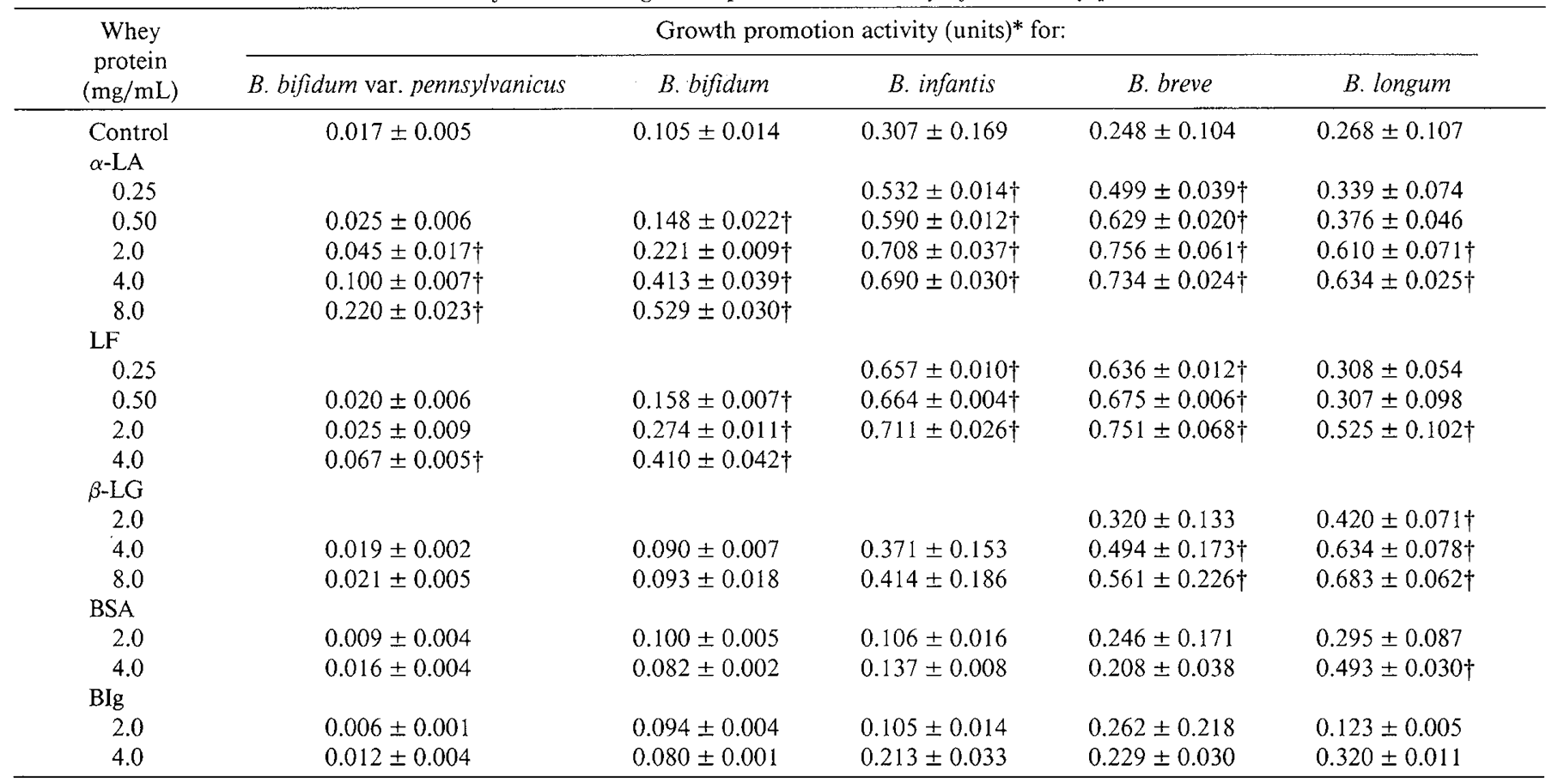

* Units defined as the amount of $\mathrm{NaOH}$ required to neutralize the acid produced after $48 \mathrm{~h}$ incubation per $4 \mathrm{~mL}$ culture. Results are given as means \pm SD of at least quadruplicate samples.

$\dagger$ Greater than saline control $(p<0.05)$.

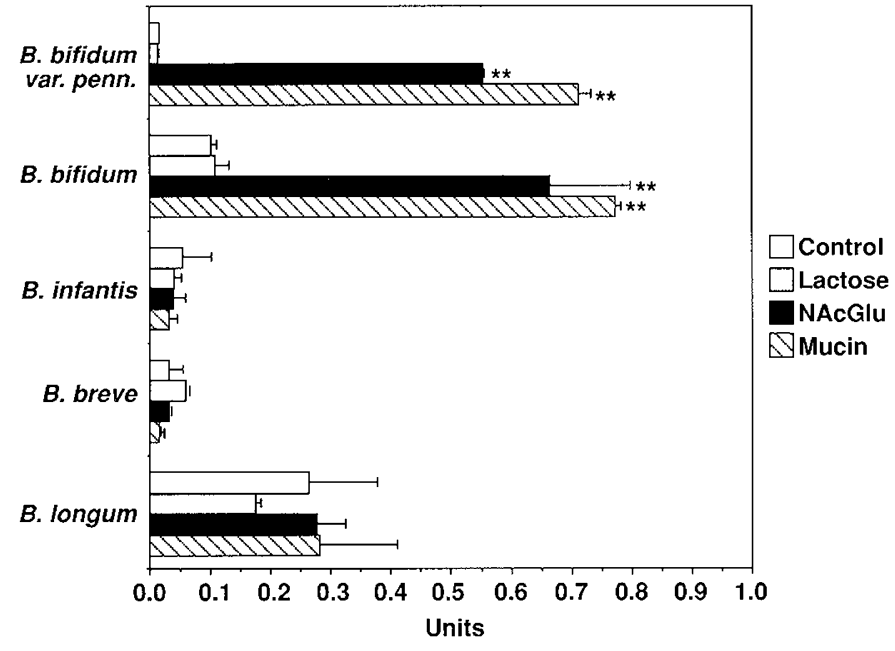

Fig. 3. Growth-promotion activity of NAcGlu, purified gastric mucin, and lactose for five strains of bifidobacteria. Test concentrations were as follows: NAcGlu, $2 \mathrm{mg} / \mathrm{mL}$; gastric mucin, $1 \mathrm{mg} / \mathrm{mL}$; lactose, $40 \mathrm{mg} / \mathrm{mL}$. The data shown represent the means $\pm \mathrm{SD}$ from at least quadruplicate samples after correcting for control growth using $1 \mathrm{~mL}$ saline $/ 4 \mathrm{~mL}$ culture. ${ }^{* *} P<0.01$ compared with saline control.

but was typically lowest and most variable for B. bifidum var. pennsylvanicus.

The NPN and PN fractions from ultrafiltered CM whey, along with unfractionated $\mathrm{CM}$ whey, were also assayed for bifidobacteria growth-promotion activity. Both the NPN and PN fractions from CM whey contained significant growth-promotion activity for three of the five test bifidobacteria strains (Table 3). All of the activity of $\mathrm{CM}$ whey for $B$. bifidum var. pennsylvanicus was found to be associated with the filtrate, whereas both the NPN and whey protein-containing PN fraction were active for $B$. bifidum, $B$. infantis, and $B$. breve. The activity of the $C M$ whey NPN and PN for $B$. longum was comparable and not significantly different from controls $(p>0.05)$.
Growth-promotion activity of purified $C M$ whey proteins. Because at least a portion of the bifidobacteria growth-promotion activity of CM whey appeared to be associated with whey proteins, we next compared the activity of individual $\mathrm{CM}$ whey proteins at various concentrations. The purity of test proteins $\beta$ LG, BSA, and BIg was $95 \%$ as claimed by the vendor and verified by PAGE (data not shown). The purity of $\alpha$-LA and LF samples was estimated to be 90 and $85 \%$, respectively, by PAGE.

Only $\alpha$-LA and LF were found to promote the growth of all five test strains of bifidobacteria (Table 4). The growth of $B$. infantis and $B$. breve was promoted by concentrations of $\alpha$-LA and $\mathrm{LF}$ as low as $0.25 \mathrm{mg} / \mathrm{mL}(p<0.05$ versus control). $B$. bifidum showed enhanced growth by $\alpha$-LA and LF at concentrations of $0.5 \mathrm{mg} / \mathrm{mL}$ or higher. Both $\alpha-\mathrm{LA}$ and LF were much less active for $B$. bifidum var. pennsylvanicus and $B$. longum, requiring levels of $2-4 \mathrm{mg} / \mathrm{mL}$ for growth promotion. BSA and BIg were inactive at levels as high as $4 \mathrm{mg} / \mathrm{mL}$ for $B$. infantis, $B$. breve, and both test strains of $B$. bifidum. $\beta$-LG was only active for $B$. breve and $B$. longum when present at relatively high concentrations ( $\geq 2 \mathrm{mg} / \mathrm{mL}$ ).

Because individual whey proteins are normally present at different levels in $\mathrm{CM}$ whey $(27,28)$, we also compared the activity of each whey protein at levels representing their proportional distribution in levels of CM whey $(2 \mathrm{mg} / \mathrm{mL})$ previously found to be active (Table 3$). \beta$-LG $(1.14 \mathrm{mg} / \mathrm{mL})$, the predominant protein in $\mathrm{CM}$ whey, was slightly active for only $B$. longum, whereas $\alpha$-LA $(0.44 \mathrm{mg} / \mathrm{mL})$ and $\operatorname{LF}(0.10 \mathrm{mg} / \mathrm{mL})$ were active for $B$. bifidum, $B$. infantis, and $B$. breve (data not shown). BSA $(0.15 \mathrm{mg} / \mathrm{mL})$ and $\mathrm{BIg}(0.26 \mathrm{mg} / \mathrm{mL})$ were both inactive for all test strains of bifidobacteria.

Growth response to carbohydrate promoters. NAcGlu, a known growth promoter for $B$. bifidum var. pennsylvanicus, and a purified oligosaccharide that contains NAcGlu (gastric mucin) were also tested for bifidobacteria growth-promotion activity. The activity of lactose was determined for comparison purposes. As shown in Figure 3, NAcGlu $(2 \mathrm{mg} / \mathrm{mL})$ and gastric mucin (1 $\mathrm{mg} / \mathrm{mL}$ ) promoted the growth of $B$. bifidum var. pennsylvanicus and $B$. bifidum but were inactive for $B$. infantis, $B$. breve, and $B$. longum. Lactose did not promote the growth of any of the five 
test strains of bifidobacteria when tested at a level that exists in CM whey $(40 \mathrm{mg} / \mathrm{mL})$.

\section{DISCUSSION}

Our investigation revealed that both protein and carbohydrate constituents in HM or CM samples may serve as growth promoters for Bifidobacterium species. In screening HM samples from 10 healthy mothers of various lactation stages, we found considerable variation in growth-promotion activity in HM samples for $B$. bifidum var. pennsylvanicus, B. infantis, and $B$. breve. The activity profile for the three bifidobacteria strains used in our study varied among individual HM samples. Bezkorovainy and Topouzian (11) also found variable growth-promotion activity in individual milk samples for B. bifidum var. pennsylvanicus.

A relatively large proportion of the nitrogen in HM (about $25 \%$ ) is not associated with protein and is loosely termed NPN, which comprises a heterogeneous group of low molecular weight, $\mathrm{N}$-containing compounds including various oligosaccharides, glycoproteins, amino acids, peptides, urea, ammonia, and creatinine (20). After ultrafiltration fractionation of a single HM sample (no. 88), we found that NPN factors (mol wt $<10000$ ) were capable of promoting the growth of $B$. bifidum var. pennsylvanicus, $B$. bifidum, $B$. breve, and $B$. longum. The activity of this NPN fraction for $B$. bifidum var. pennsylvanicus was most likely due to $\mathrm{N}$-containing oligosaccharides or glycoproteins as previously reported $(10,14,16)$. The $\mathrm{PN}$ fraction (mol wt $>$ 10000 ) of HM, which contained both whey and casein proteins, was active for only $B$. bifidum var. pennsylvanicus and $B$. breve. Previous studies by several investigators have led to the belief that bifidobacteria growth promoters are present in HM, absent in CM, and consist of a variety of NAcGlu-containing oligosaccharides or glycoproteins $(6,11,16,26)$. These conclusions are based primarily on the growth response of $B$. bifidum var. pennsylvanicus. However, this model strain is unable to utilize glucose and requires D-glucosamine derivatives for cell wall synthesis (29). Therefore, results obtained with B. bifidum var. pennsylvanicus may not accurately reflect the typical response of the genus Bifidobacterium to HM or CM growth promoters. Furthermore, B. bifidum var. pennsylvanicus is not a major component of the intestinal microflora of the infant. Results obtained in this study using HM samples and fractionated HM support the possibility that both protein and nonprotein components in HM promote the growth of bifidobacteria and support the findings of Beerens et al. (6), which demonstrated that growth of $B$. bifidum, $B$. infantis, and $B$. longum was promoted by different factors in HM.

We also compared the growth-promotion activity of CM samples from eight different farms in four states for three bifidobacteria strains. We chose to screen "herd milks" rather than individual CM samples to determine bifidobacteria growth-promotion activity in milk used for producing commercial milk or milkbased infant formulas, which would come from bulk milk on individual farms rather than from individual cows. Bulk CM samples showed little variation in activity for $B$. bifidum var. pennsylvanicus, $B$. infantis, and $B$. breve. It should be recognized however, that milk samples from individual cows may be more variable in activity for strains of bifidobacteria than milk pooled from many animals. The activity of $\mathrm{CM}$ whey for $B$. bifidum var. pennsylvanicus was found only in the NPN fraction, suggesting that $\mathrm{N}$-substituted $\mathrm{D}$-glucosamine residues are present and available in nonprotein components but not intact whey proteins. Growth-promotion activity for B. bifidum, B. infantis, and $B$. breve was present in both the whey NPN and PN fractions.

The major whey proteins in CM include $\beta$-LG, $\alpha$-LA, serum albumin, Ig, and LF, which collectively comprise about $90 \%$ of the protein in $\mathrm{CM}$ whey $(27,28)$. We confirmed that whey proteins are at least partially responsible for the growth-promotion activity in $\mathrm{CM}$ whey by testing purified $\mathrm{CM}$ whey proteins. $\alpha^{\left.{ }^{\prime}\right\lrcorner \mathrm{A}}$ and LF, a milk protein ordinarily associated with bacter- iostasis, were the two most active whey proteins, showing the greatest activity for $B$. infantis and $B$. breve. $\alpha-\mathrm{LA}$ and LF were less active for $B$. bifidum. BIg and BSA were inactive, whereas $\beta$-LG, the major whey protein found in $\mathrm{CM}$ whey $(27,28)$, was active at only high concentrations and only for $B$. longum.

In summary, we found that CM whey and HM appear to contain multiple factors that are capable of promoting the growth of intestinal strains of bifidobacteria from infants. Activity in CM whey is associated with both protein (especially $\alpha$-LA and LF) and nonprotein components. The nature of the nonprotein factors in CM whey that promote the growth of bifidobacteria is not known. Our results also demonstrate that strains of bifidobacteria differ in responsiveness to growth promoters in $\mathrm{CM}$ depending on whether they are NAcGlu-based or protein. NAcGlu and gastric mucin, a complex oligosaccharide that is known to contain NAcGlu, promoted significant growth of $B$. bifidum var. pennsylvanicus and $B$. bifidum, whereas whey proteins were generally poor growth promoters for these strains. Conversely, LF and $\alpha$-LA served as good growth promoters for $B$. infantis, $B$. breve, and $B$. longum, whereas NAcGlu and gastric mucin were inactive. The well-recognized role of HM oligosaccharides as bifidobacteria growth promoters is based primarily on the response of $B$. bifidum var. pennsylvanicus. However, our report demonstrates that species of bifidobacteria that are commonly found in the intestinal tract of infants do not respond to NAcGlu-based promoters, underscoring the need to use clinically relevant species of bifidobacteria when studying growth-promoting factors.

Acknowledgments. The authors thank Yung H. Lee for technical assistance and Janet L. Debes for secretarial support.

\section{REFERENCES}

1. Mitsuoka T 1982 Recent trends in research on intestinal flora. Bifidobacteria Microflora 1:3-24

2. Benno Y, Sawada K, Mitsuoka T 1984 The intestinal microflora of infants: composition of fecal flora in breast-fed and bottle-fed infants. Microbiol Immunol 28:975-986

3. Mitsuoka T, Kaneuchi C 1977 Ecology of the bifidobacteria. Am J Clin Nutr 30:1799-1810

4. Stark PL, Lee A 1982 The microbial ecology of the large bowel of breast-fed and formula-fed infants during the first year of life. J Med Microbiol 15:189203

5. Yoshioka H, Iseki K, Fujita K 1983 Development and differences of intestinal flora in the neonatal period in breast-fed and bottle-fed infants. Pediatrics $72: 317-321$

6. Beerens $\mathrm{H}$, Romond $\mathrm{C}$, Neut C 1980 Influence of breast-feeding on the bifid flora of the newborn intestine. Am J Clin Nutr 33:2434-2439

7. Kovar MG, Serdula MK, Marks JS, Frasner DW 1985 Review of the epidemiologic evidence for an association between infant feeding and infant health. Pediatrics 75(suppl):615-638

8. Bullen CL, Tearle PV, Willis AT 1976 Bifidobacteria in the intestinal tract of infants: an in vivo study. $\mathrm{J}$ Med Microbiol 9:325-333

9. Bullen CL, Tearle PV 1976 Bifidobacteria in the intestinal tract of infants: an in vitro study. J Med Microbiol 9:335-344

10. Bezkorovainy A, Nichols JH 1976 Glycoproteins from mature human milk whey. Pediatr Res 10:1-5

11. Bezkorovainy A, Topouzian N 1981 Bifidobacterium bifidus var pennsylvanicus growth promoting activity of human milk casein and its derivatives. Int J Biochem 13.585-590

12. Porter P 1979 Adoptive immunization of the neonate by breast factors. In Ogra PL, Dayton DH (eds) Immunology of Breast Milk. Raven Publishing, New York, pp 197-206

13. Gyorgy P 1953 A hitherto unrecognized biochemical difference between human milk and cow's milk. Pediatrics 11:98-107

14. Gyorgy P, Kuhn R, Rose CS, Zilliken F 1954 Bifidus factor. 2. Its occurrence in milk from different species and in other natural products. Arch Biochem Biophys 48:202-208

15. Bezkorovainy A, Grohlich D, Nichols JH 1979 Isolation of a glycopolypeptide fraction with Lactobacillus bifidus subspecies pennsylvanicus growth-promoting activity from whole human milk casein. Am J Clin Nutr 32:14281432

16. Nichols JH, Bezkorovainy A, Landau W 1974 Human colostral whey M-1 glycoproteins and their $L$. bifidus var. penn. growth promoting activities. Life Sci 14:967-976

17. Azuma N, Yamauchi K, Mitsuoka T 1984 Bifidus growth-promoting activity of a glycomacropeptide derived from human $k$-casein. Agric Biol Chem 48:2159-2162 
18. Kehagias C, Jao YC, Mikolajcik EM, Hansen PMT 1977 Growth response of Bifidobacterium bifidum to a hydrolytic product isolated from bovine casein. J Food Sci 42:146-150

19. Petschow BW, Talbott RD 1990 Growth promotion of Bifidobacterium species by whey and casein fractions from human and bovine milk. J Clin Microbiol 28:287-292

20. Lonnerdal B, Woodhouse LR, Glazier C, 1987 Compartmentalization and quantitation of protein in human milk. J Nutr 117:1385-1395

21. Packard VS 1982 Macronutrients and Energy. In: Stewart GF, Schweigert BS, Hawthorn J (eds) Human Milk and Infant Formula. Academic Press, New York, pp 7-28

22. Poupard JA, Husain I, Norris RF 1973 Biology of the bifidobacteria. Bacteriol Rev 37:136-165

23. Variyam EP, Hoskins LC 1981 Mucin degradation in human colon ecosystems. Gastroenterol 81:751-758
24. Dubois M, Gilles KA, Hamilton JK, Rebers PA, Smith F 1956 Colorimetric method for determination of sugars and related substance. Anal Chem 28:350-355

25. Hartree EF 1971 Determination of protein: a modification of the Lowry method that gives a linear photometric response. Anal Biochem 48:422-427

26. Poch M, Bezkorovainy A 1988 Growth enhancing supplements for various species of the genus Bifidobacterium. J Dairy Sci 71:3214-3221

27. Eigel WN, Butler JE, Ernstrom CA, Farrell HM, Harwalkas VR, Jenness R, McWhitney R 1984 Nomenclature of proteins of cow's milk, 5th Revision. J Dairy Sci 67:1599-1631

28. Gordon WG, Kalan EB 1974 Proteins of milk. In: Webb BH, Johnson AH, Alford JA (eds) Fundamentals of Dairy Chemistry. AVI Publishing Co, Westport, CT, pp 87-124

29. Veerkamp JH 1969 Uptake and metabolism of derivatives of 2-deoxy-2-aminoD-glucose in Bifidobacterium bifidum var pennsylvanicus. Arch Biochem Biophys 129:248-256

\section{Announcement}

The Second International Symposium on Clinical, Biochemical, and Molecular Aspects of Fatty Acid Oxidation will be held at the Sheraton Society Hill Hotel in Philadelphia, PA on November 3-6, 1991. Coorganizers of the Symposium are Paul M. Coates, Ph.D. and Kay Tanaka, M.D.

For information regarding registration and submission of abstracts, please contact: Paul M. Coates, Ph.D., Division of GI and Nutrition, The Children's Hospital of Philadelphia, 34th St. and Civic Center Blvd., Philadelphia, PA 19104.

Deadline for registration and abstracts is June 1, 1991. Registration will be limited to 175 participants. 